\title{
Analysis on Problems and its Countermeasures of Accurate Poverty Alleviation
}

\section{Yu He}

Sichuan Agricultural University, Chengdu, Sichuan, 611130

\author{
Keywords: Accurate Poverty Alleviation; Establishing Documents and Cards; Policy Tilt; \\ Industrial Poverty Alleviation
}

\begin{abstract}
Since the 18th CPC National Congress, the precise poverty alleviation has become an important strategic guide for poverty alleviation and development in our country in the new era. However, in actual operation, there are still many deficiencies in precision poverty alleviation. This article focuses on analyzing the problems existing in the accurate poverty alleviation work from the aspects of the accreditation procedure, object participation and policy implementation, and puts forward countermeasures and suggestions from the strict discipline, establishing the mechanism to alleviate poverty in the industry and improving the work style of the grassroots cadres so that the precise poverty alleviation To be effective, improve poverty alleviation efficiency, and achieve all-round precision out of poverty..
\end{abstract}

\section{Introduction}

Eradicating poverty and improving people's livelihood are the embodiment of our party's principle of serving the people wholeheartedly. Since the 18th CPC National Congress, the Central Committee has made unprecedented efforts to reduce poverty. When it proposes that a well-off society be built in an all-round way, according to the current standards, all rural population should be lifted out of poverty on schedule and all poor counties should reduce their poverty and pull off hats. After many years of unremitting efforts and the launching of various poverty alleviation projects, the status quo of poverty in our country has been somewhat improved. However, we should clearly see that there are still many problems in the current poverty alleviation work. All these problems are expected to be alleviated in the future It is urgent to solve.

\section{The Deficiencies}

There are significant differences in the policy of getting rid of poverty in Sichuan Province, which is mainly reflected in the differences in industrial support between the four major films, 88 key poverty-hit counties and other general counties identified by the state. The differences in policies between provinces and municipalities are inconsistent with those promulgated by provinces and municipalities such as medical and health care, education support and poverty alleviation microfinance, which are mainly reflected in inconsistent enjoyment of policies in scope and to some extent competition among poor people such as asbestos and immediate vicinity Mianning anti-poverty treatment there are more differences.

Policy differences have also brought some problems to the precise poverty alleviation work. After the implementation of the policy to rid the poor, if a county is a county of treatment, it does not belong to one of the four regions and is not one of the 88 key counties. Not only is there no greater Policy support, some of the original policy also faces cancellation. For example, on the issue of getting rid of poverty, the 88 key counties in the four major districts continue to enjoy the policy of helping the poor, such as medical care, education and industrial support. The discussions and surveys show that in other areas such as medical care and education, there are " "The plight of ex-poor families in the rapid increase in the proportion of medical expenses, even if the maximum protection of $90 \%$ of the serious illness, may once again face the look down on the dilemma. Some peasant households have special diseases, they need to go to private hospitals for treatment, medical expenses can not be reimbursed, and expensive medical expenses account for a large part of the 
expenses of poor households (including many non-poor households in poor areas). To a certain extent, this has affected the willingness to get out of poverty and the effect of poverty alleviation. In particular, poor households with a relatively large proportion of income from transfer of income may face declining industrial support and medical expenses as they withdraw from the poverty-stricken households. This will result in a decrease in income. In particular, poor households that have just passed the "pass line" by relying on property transfer income are highly likely to return to poverty, affecting the stability and effectiveness of poverty eradication.

Four-week poverty-stricken areas surrounded by mountains, affected by the terrain, most of the poor households settled in the mountainside, a serious shortage of arable land. Low-mountain development Huangguogan, loquat in the development of low mountains, development of walnut mountains, occupy a lot of cultivated land. Huangguogan citrus industry has become the scale of the scale, poverty alleviation effect is obvious, but poor households are mainly concentrated in the high altitude mountains, these areas are generally not suitable for the cultivation of Huangguogan, coupled with the planting industry income cycle is slow, poor Household income less. Most poor households in recent years, home grown walnuts have not yet entered the fruiting year, the government promoted the cultivation of loquat suffered two consecutive years of freezing damage without harvest. In addition, many poor households lack knowledge and plan for the cultivation of Huangguogan, loquat and walnut, which not only may result in no gains, but also cause a lot of losses. This shows that the effect of alleviating poverty in the industry is still not obvious enough and needs to be further broken down in many aspects such as industrial adequacy, industrial scale and industrial efficiency.

According to the visits and village cadres' reflection, problems have been found in the earlier inclusion work of poor households. Some families that are not in the poverty line have also been included in the poor households, reflecting the inaccurate accuracy of the original accurate recognition rate.

The survey shows that although the village cadres' propaganda and introduction, poor households generally have some understanding of poverty alleviation and poverty alleviation policies, but the general understanding is not enough in breadth and depth. Most of the graduates who are out of poverty have a low level of education and are illiterate. The poor understanding of poverty alleviation policies shows that the propaganda efforts of grassroots cadres and local media are not sufficiently advanced to promote poverty alleviation and poverty alleviation. The publicity needs to be further strengthened.

Survey found that the county offensive plan for poverty alleviation, the implementation of the project to be about 200, invested about 500000000 yuan, counties can not afford the financial resources, a larger funding gap.

As for income and expenditure of production and operation, the income and expenditure accounts posted in front of poor households tend to be fully converted into incomes for self-produced food and hogs, but in fact, they generally do not generate any money income.

For the calculation of labor income, the module did not give full consideration to the living expenses of migrant workers, nor did it fully investigate whether the migrant workers used the migrant workers' income for household expenditures. This would result in an overestimation of the annual per capita income of migrant workers.

In the aspect of income account, very few poor households can accurately report their annual incomes and annual expenditures, even though there are no bills on their doorsteps, nor do they have original receipts and payments. The incomes posted at the entrance tend to be higher and lower than the actual income, or even seriously out of line. The two main items of operating income and operating expenses are estimates, rather than actual figures.

Some leading cadres are not familiar with the business of the department in charge and are not familiar with the policies and regulations in charge of work so that they can not accurately grasp the ideological trends of farmers and can not grasp the social conditions and public opinions. In addition, some village staff did not have enough training on poverty alleviation work, which led to the extension of the cycle of implementation of the anti-poverty policies and measures, with 
insignificant effect. The first secretary of the village, the village agricultural technicians and other business needs to be improved, most of the next sent agricultural technicians from agencies, the lack of in-depth understanding of rural areas, agriculture and peasants, and some staff failed to identify their own position in time, Correctly assume the responsibility of rural policy advocacy, upper and lower information communication, mass petition mediation, farmer rich service and organization construction supervision.

Village cadres attend the conference sign-in system, and some county-level leaders to the village inspection signature is not standardized, the village under the guidance of the work did not sign in time, leading to sign in the handwriting of an article. Some village villagers' congress democratically reviewed the minutes of the meeting, and the list of the exiting villages in the poor villages lacks the signature of the first secretary in the village and the principal leaders of towns and villages. Help unit work record is not clear. There is no approval unit and labeling time in the sign-up book of the democratic review meeting record, which is not conducive to the review of the anti-poverty work in the future. Part of the village cadres failed to perform their duties, perfunctory and responsible for the work within the scope of their duties, some of the staff members of the helping units only in place, do not seek due diligence exists.

The infrastructure is weak, especially in the construction of roads. Although the "village-through roads" are implemented in impoverished areas, they are still only accessible to the village departments and small villages. Many village groups and villagers have no access to natural settlements. The roads from the village to the rest of the group have not been hardened, and the location of poor households is basically beyond the coverage of the hardened roads. Most of the poor households hope that the hardened roads can be reached at home. In addition, the grade of road construction is of poor quality, follow-up of village road maintenance is slow, and the hardened roads in Tong Village are of different hardened roads with far-reaching traffic accessibility, villagers are going out and transportation costs are high, and another one Tong village road hardening work, transportation problems are still the key to restricting the economic development in poverty-stricken areas.

Part of the relocation of peasant household water use electricity problems, and the villagers water hoses easily damaged, or washed away by floods, or by livestock, villagers drinking water facilities to be further toughened; voltage instability affect the daily electricity consumption of villagers. Murakami health environment is poor, the lack of refuse collection ponds, littering phenomenon is more serious, villagers dump garbage into the ditch, causing secondary pollution.

Poor and slow industrial development in a single, the industrial structure is irrational, poverty alleviation industry with strong homogeneity, no stable, long-term support for the dominant industries, most of the planting industry, the main are flue-cured tobacco, green pepper, walnut, once Encountering a natural disaster, the loss is serious, and the sustainability of farmers' income can not be optimistic. It is extremely easy to have the phenomenon of "returning to poverty". Specialization of agricultural industry needs to be strengthened. The research achievements and practical techniques applied to planting and livestock husbandry in minority areas are backward, including the breeding of fine seeds, the application of fertilizers, the prevention and control of pests and diseases, cultivation and culture techniques, the processing of agricultural and sideline products, preservation, storage and transportation technologies, agricultural machinery technology, Farmland water conservancy, soil improvement and soil and water conservation technologies, agricultural environmental protection technologies. Farmers have a low level of education and have not been professionally trained to master agricultural extension technologies.

\section{Countermeasures and Suggestions}

At present, the training of leading cadres generally focuses on the training of political theoretical qualifications and ignores business training. Training of leading cadres' political theoretical literacy should be prior to the promotion and appointment, and after the promotion, the training of leading cadres should be focused on strengthening business training for leaders The training of cadres in their division of labor will help leading cadres become familiar with their business knowledge and 
business policies so that they can carry out their work better. Perfecting and perfecting the learning and training system clearly stipulates that village cadres should concentrate on studying once a week and vigorously enhance the overall quality of village cadres. Especially for the first secretary and the village agricultural technicians in business training, their contact with farmers more direct and more closely to strengthen the guidance of agricultural technicians to the village and improve the level of their own rural workers, so as to more effectively Conduct technical guidance.

Strengthen village-level poverty alleviation archives management, special management of all kinds of archives data, special management. Improve and perfect village cadre meeting system, so that village cadres have clear goals for job responsibilities. For some of the village cadres omission, chaos as a problem, the development of evaluation and evaluation system and the system of punishment, strengthen the supervision and assessment of village cadres. Strict implementation of village affairs open, so that villagers have direct supervisory authority over the behavior of village cadres. We should further cultivate the responsibility and actively cultivate the ability of the party members and the cadres to bring about poverty and wealth. We should give play to the role of "leader" to strengthen the building of grassroots poverty alleviation teams and link the "last mile" with precise poverty alleviation. We should introduce and rationally allocate full-time poverty alleviation personnel and strengthen the precise poverty alleviation workforce Enhance the continuity and combat effectiveness of poverty alleviation work at the grassroots level, ensure full-time and dedicated work, maintain a stable workforce, clarify the powers and responsibilities, work well and continuously improve the modernization of poor rural governance and governance.

"If we want to get rich, we must first build a road" and we should increase the policy support of Tong Village Highway. Infrastructure construction in underdeveloped areas lags behind, with the most prominent village-village road in rural areas. According to the current rural village road construction policy, hardening the road to the village committee means that the village village road construction is completed, and most of the village committee site selection in the traffic is relatively convenient place, part of the set at the edge of the village, village road radiation Driven by the development of the entire village, the people are eagerly looking forward to the village road can truly achieve unobstructed village road. To this end, it is proposed to increase rural areas in poor areas of highway policy support, the entire village of rural village construction into the village road construction category. In addition, we should also strengthen the construction of other infrastructures, intensify the construction of drinking water safety projects in rural areas and toughen the drinking water facilities; intensify the construction of rural power facilities, transform the rural power grids and solve the problem of voltage instability. Improve rural health and environmental conditions, the development of rural environmental protection incentives.

Scientific innovation, bigger and stronger industrial development in poor areas, increase the intensity of the industry to alleviate poverty. In accordance with the overall requirements of "organizing the masses, developing industries, strengthening brands and docking the market", we should scientifically explore the path of development of poor households' industries and actively encourage and encourage poor people to develop high-quality industries and comprehensively establish a system of industrial development combining short-term, medium-term and long-term , Develop heterogeneous poverty alleviation industries, introduce more specialized organizations, improve industrial structure, find and develop local agricultural products economy, and form local industry brands so as to achieve the sustainability of industrial development and bring the poor people to prosperity. Actively cultivate pillar industries to ensure that agricultural efficiency farmers continue to increase income. We should make full use of all kinds of resource advantages in the region, insist that tourism should be swamped, farmers should be farmers, workers should be workers, merchants should be advised to cultivate and support the development of rural specialty industries (such as walnuts and green pepper), and increase agriculture Industrialization leading enterprises to support efforts to establish and improve the "enterprise + cooperative + base + farmers" chain of interest mechanism to encourage public entrepreneurship to promote employment, enhance the vitality of poverty-stricken areas, and comprehensively enhance the income of poor families. At the same time, it is necessary to attach importance to the issue of good government 
policies and less implementation of localities, pay attention to the organic combination of industrial development with the actual conditions of the region and the needs of rural households, and give equal emphasis to the rural collective economy and the local industries and mutually promote the organic development.

The policy disruption to the accurate poverty alleviation work in Shimian County as a whole, especially to the populace areas of Tibetans and Yi people, not only needs to have sufficient understanding, but also should be actively reported, explained, explained and sought for by higher level policies. Especially for the people who are poor because of illness and get rid of poverty due to policies, the decoupling of medical claims after poverty alleviation will have a great negative effect on the effect of poverty alleviation. We should actively strive to win and keep "getting rid of poverty". In addition, asbestos poverty alleviation industry development plan needs a lot of financial support, these sources of funds depend in part on the sustainability of industrial support policies need municipalities and counties to actively fight for.

For some poor households in the leading industries ineffective production, it is recommended to implement the system of performance evaluation of industry, and the evaluation results and support for poor households linked to the supervision of those with the ability to work actively involved in production. The main body of the industrial performance appraisal may be the agricultural technician. Regular inspection and evaluation shall be conducted on the industrial production of each poor household. Impoverished households with poor production or abandoned industries shall be given a chance to make rectification and special technical guidance will be provided. To the standard of poor households, in order to reduce the amount of direct financial subsidies as a punishment for the evaluation results exceeded the standard of poor households, appropriate to increase their efforts to help the industry.

For per capita annual income of 3100-4100 yuan, and relying on financial transfer of income-based, easily return to poverty of the statistical population should carefully develop a comprehensive anti-poverty mechanism, including improving the poverty monitoring system to strengthen the follow-up survey of poor farmers and follow-up stand by. To establish files for off-poverty households and follow-up services, to timely and accurately grasp the production and living conditions of the poor after their retirement from poverty, to further strengthen social security such as pensions, health care and education, and to timely solve their difficulties and problems in production and life and prevent poverty Due to disaster, return to poverty due to illness.

We will fully implement the system of checking the receipts and disbursements of poor households in establishing credit cards, accurately record the basic conditions and receipts and expenditures of poor households, dynamically control the overall situation of accurate poverty alleviation, and promptly inspect and supervise the work style and ability of cadres. Pairs of assistants assist the poor households to keep a monthly (every ten days) income and expense account and keep the original vouchers, signed by helping responsible persons and poor households to confirm that poor households visit "households to meet" and receive Support account records "pen clear." Improve the help record card, a detailed record of each help content and funding sources to eliminate ambiguity, the phenomenon of unclear responsibility.

\section{References}

[1] Zhang Hongyu, Zhang Tao, Sun Xiuyan, et al. How to develop agricultural productive service industry in large agricultural counties - research and thinking of Sichuan [J]. Agricultural Economics, 2015 (12): 3-7.

[2] Chen Dingyang. Research on the Mechanism of Modern Agricultural Industrialization from the Perspective of Supply-side Reform - Mechanism, Operational Mechanism and Empirical Analysis [J]. Progress in Science and Technology, 2016, 33 (13): 78-83.

[3] Gao Qiang, Zhao Hai. Construction of Japanese Agricultural Management System and Its Enlightenment to China [J]. Journal of Modern Japanese Economy, 2015 (3). 
[4] Zhang Shemei, Chen Wenkuan, Deng Yulin. Investigation and Research on Constructing New Agricultural Production and Operation System under the Background of Land Circulation [J]. Economic Literacy, 2014 (2): 43-48

[5] Liu Tongshan, Mao Fei, Kong Xiangchi. Study on the Role of New-type Agricultural Managerial Entrepreneurship in Young and Middle-aged Peasants - A Case Study of Henan Province [J]. Journal of Rural Economics, 2015 (9): 104-109 